\title{
THERMAL AND PHOTOCHEMICAL GENERATION OF ELECTRONICALLY EXCITED ORGANIC MOLECULES. TETRAMETHYL-1,2-DIOXETANE AND NAPHTHVALENE
}

\author{
Nicholas J. Turro and Peter LechtKen \\ Department of Chemistry, Columbia University, \\ New York, NY 10027, USA
}

\begin{abstract}
In this paper some examples of reactions which yield electronically excited products are presented. In particular, the 1,2-dioxetanes are discussed. These molecules cleave cleanly into two carbonyl fragments when heated or irradiated. It will be shown that these simple, high energy, four atom arrays can efficiently generate electronically excited carbonyl fragments when they decompose. Surprisingly, tetramethyl-1,2-dioxetane (V) yields acetone triplet selectively upon thermolysis or photolysis.

A study of the kinetics of thermal decomposition of $\mathrm{V}$ as a function of solvent, and the mechanistic implications of these observations will be discussed. Based on summation of available evidence, we propose that the thermolyses of 1,2-dioxetanes require specific vibrational motions which enhance spin-orbit coupling as the molecule fragments, and allow efficient decomposition into triplet states.

In the photochemistry of $\mathrm{V}$ an exceptional 'anti-Stokes' sensitization is demonstrated, which suggests the possibility of efficient execution of 'blue light' photochemistry with 'red light', and a 'quantum chain' reaction.

It is demonstrated that, at $77^{\circ} \mathrm{K}$, naphthvalene undergoes efficient photochemical conversion to naphthalene triplets.

Finally, the relationship of radiationless electronic relaxation and primary photochemical processes is discussed in the framework of our results.
\end{abstract}

\section{INTRODUCTION}

In this paper we shall be concerned with organic reactions in solution that generate electronically excited products by either thermal (equation 1) or photochemical (equation 2) activation of reactants.

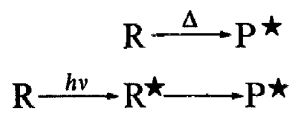

Such reactions are of potential interest to photochemists, spectroscopists, kineticists and photobiologists for any number of reasons. Photochemists may see in the study of such reactions a unique method of selectively produc- 
ing electronically excited molecules which are not easily accessible by normal means of photochemical excitation. Spectroscopists may see in such reactions a connection between the ubiquitous and imperfectly understood radiationless processes which interconvert the electronic states of a molecule and the change of electronic states implicit in reactions 1 and 2. Kineticists may be intrigued by the selective discharge, into specific groups of atoms, of sufficient chemical energy to produce an electronically excited product. Photobiologists, and the public at large, have long been fascinated by nature's display of chemielectronic pyrotechnics in fireflies and luminous plants, both of which are presumably manifestations of reaction 1 .

In spite of the potential interest of reactions such as 1 and 2, hardly any information is available concerning the mechanisms of formation of electronically excited products. We hope this paper will stimulate interest in this area by our discussion of several examples of reactions 1 and 2, which have been studied at Columbia during the last year or so. In particular, the thermal and photochemical reactions of tetramethyl-1,2-dioxetane have provided a well-suited system for detailed study of reactions 1 and 2 . In addition, the emission spectroscopy of naphthvalene also provides a particularly striking example of reaction 2 .

\section{ELECTRONIC STRUCTURE AND SPECTROSCOPY OF PEROXIDES}

The outstanding property of the peroxide linkage is surely the feeble bonding which connects the two oxygen atoms, the $\mathrm{O}-\mathrm{O}$ bond strength of organic peroxides generally being less than $39 \mathrm{kcal} / \mathrm{mole}$. This property of peroxides seems to originate in the repulsions of the non-bonded electron pairs on the adjacent oxygen atoms. A possible description of the highest energy electrons of the ground state of the peroxide bond is $\left(\pi_{\mathrm{OO}}^{\star}\right)^{2}$, i.e. the mixing of two adjacent $\mathrm{n}_{\mathrm{O}}$ orbitals causes splitting into a $\pi_{\mathrm{OO}}$ and $\pi_{\mathrm{O} O}^{\star}$ pair, each of which is doubly occupied in the ground state ${ }^{1}$. The lowest available unfilled orbital is probably of $\sigma_{\mathrm{OO}}^{\star}$ character. Thus, the lowest energy electronic transition in simple peroxides can be characterized by $\pi_{0 O}^{\star} \rightarrow \sigma_{\text {Oo }}^{\star}$. Essentially, instantaneous cleavage of the $\mathrm{O}-\mathrm{O}$ bond is clearly expected to follow electronic excitation.

Simple alkyl peroxides ${ }^{2}$ show only weak, nearly structureless end absorption in the region below $400 \mathrm{~nm}$. For example, di-tert-peroxide ${ }^{2}$ possesses an inflection $(\varepsilon \sim 5)$ at $\sim 260 \mathrm{~nm}$. We are unaware of any systematic studies or reports of emission from alkyl peroxides ${ }^{3}$. Although sketchy, the literature is consistent with the idea that the excitation $\pi_{0 O}^{\star} \rightarrow \sigma_{O O}^{\star}$ results in dissociation or predissociation.

\section{PHOTOCHEMICAL REACTIONS OF PEROXIDES}

Until recently, very little was known about the mechanistic details of the photochemistry of peroxides in solution. This situation probably results from the difficulty of direct excitation of peroxides, due to their inherently weak absorption above $250 \mathrm{~nm}$. In spite of this, the recent work of Story ${ }^{4}$ and Criegee $^{5}$ has shown that some clever and important synthetic photoreactions 
of peroxides can be achieved. For example, elegant syntheses of macrocyclic rings $^{4}$ (equation 3) and cyclobutadienes ${ }^{5}$ (equation 4) have been achieved.
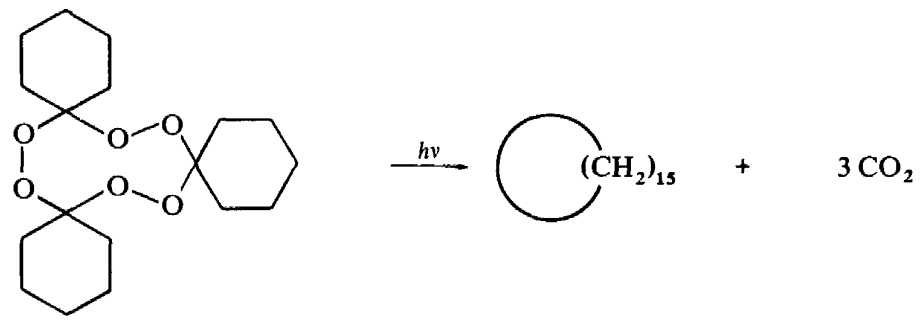<smiles>CC12OOC(C)(O1)C1(Cl)C(Cl)=C(Cl)C21Cl</smiles><smiles>ClC1=C(Cl)C(Cl)=C1Cl</smiles>

Although no detailed mechanistic work on these reactions has been reported, it seems reasonable to assume that the initial photochemical step is cleavage of the $\mathrm{O}-\mathrm{O}$ bond, followed by secondary thermal decomposition. This picture is consistent with the observation that di-tert-butyl peroxide mainly undergoes $\mathrm{O}-\mathrm{O}$ bond cleavage when it is excited with ultra-violet light $^{2}$.

Sensitized decompositions of peroxides have been reported ${ }^{3,6}$, and it appears that triplet benzophenone can effect the decomposition of dibenzoylperoxide ${ }^{6}$. This experiment suggests, but does not require, that the peroxide linkage $\mathrm{may}^{7}$ have triplets in the range of $70 \mathrm{kcal} / \mathrm{mole}$.

Perhaps the spectroscopy and photochemistry of peroxides can be summarized as follows: not very much is known, but a lot of interesting experiments remain to be done.

\section{1,2-DIOXETANES}

1,2-Dioxetanes, given by the general structure I, have been the subject of intense recent study. Such structures have been implicated in many chemiluminescent reactions ${ }^{8}$. $\alpha$-Peroxylactones such as II and III are implicated in bioluminescent reactions ${ }^{9}$ and in a commercial method of producing cold light ${ }^{10}$ via a chemiluminescent reaction. The breakthrough, pioneering synthesis of trimethyl-1,2-dioxetane by Kopecky and Mumford ${ }^{11}$ and the 1,2-addition of singlet oxygen to electron rich and hindered ethylenes achieved by Foote and Mazur ${ }^{12}$, Bartlett and Schaap ${ }^{13}$, and the recent work of Adam et al. ${ }^{14}$, and Richardson ${ }^{15}$ et al., represent a monumental step forward for the study of intriguing, reactive but isolable intermediates. The recent proposal that dioxetanes are intermediates in the ozonolysis of alkenes by Story ${ }^{16}$ may signal yet another breakthrough in the synthesis of this family of remarkable cyclic peroxides.

These isolable molecules are remarkable in that they are kinetically stable at $300^{\circ} \mathrm{K}$, in spite of the fact that they release about $100 \mathrm{kcal} / \mathrm{mole}$ in heat and, 
in addition, about $6-10 \mathrm{kcal} / \mathrm{mole}$ of positive entropy when they dissociate into two carbonyl fragments (equation 5), a reaction common to all 1,2dioxetanes. Thus, there is effective energy storage in a structurally simple four atom array which superficially looks capable of 'busting up' by a relatively uncomplicated chemical reorganization.<smiles>[R]C1([R])OOC1([R])[R]</smiles>

I<smiles>[R]C1([R])OOC1=O</smiles>

II<smiles>O=C1OOC1=O</smiles>

III<smiles>[Y]1[Y]OOO1</smiles>

IV

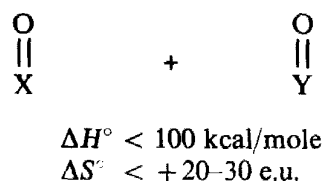

Reactions conforming to equation 5 are generally chemiluminescent, i.e. enough energy is funnelled into a fragment so as to produce electronic excitation and eventual emission from that moiety. An extraordinary property has been proposed $d^{8}$ for molecules of type IV in this regard: that their decomposition can be catalysed by electronic energy acceptors!

Chemists who delight in the study of molecules possessing high energy content can not only probe into the reasons underlying the fantastic kinetic stability of 1,2-dioxetanes, but they can also design experiments to answer such questions as: (1) can a reaction be slow because it is too exothermic? (2) is there a chemical equivalent to the Franck-Condon principle which prevents massive release of chemical energy into vibrational energy? (3) are orbital symmetry factors operating? (4) what are the yields, multiplicities and mechanisms of formation of the electronically excited states responsible for the chemiluminescence in reactions of type 5? (5) can energy acceptors really 'catalyse' the decomposition of dioxetanes and if so, what is the mechanism of such an astonishing reaction?

\section{SPECTROSCOPY AND PHOTOCHEMISTRY OF 1,2-DIOXETANES}

Tuble 1 lists a number of 1,2-dioxetanes that have been reported in the literature. We shall discuss the kinetic parameters there listed later in this paper. The molecule, tetramethyl-1,2-dioxetane (V), is of special interest to us here, since it represents the only alkyl dioxetane which is expected to yield identical carbonyl fragments upon decomposition. Furthermore, our prior interests in the solution photochemistry of acetone allow us a splendid opportunity to search rationally for the electronically excited states of acetone when $\mathrm{V}$ is fragmented ${ }^{17}$.

The exceptional electronic characteristics to be expected of 1,2-dioxetanes are apparent by simple visual observation of tetramethyl-1,2-dioxetane, which is a yellow, low melting solid. The ultra-violet absorption spectrum of 
ELECTRONICALLY EXCITED ORGANIC MOLECULES

Table 1. The kinetic parameters of some isolable 1,2-dioxetanes and related systems

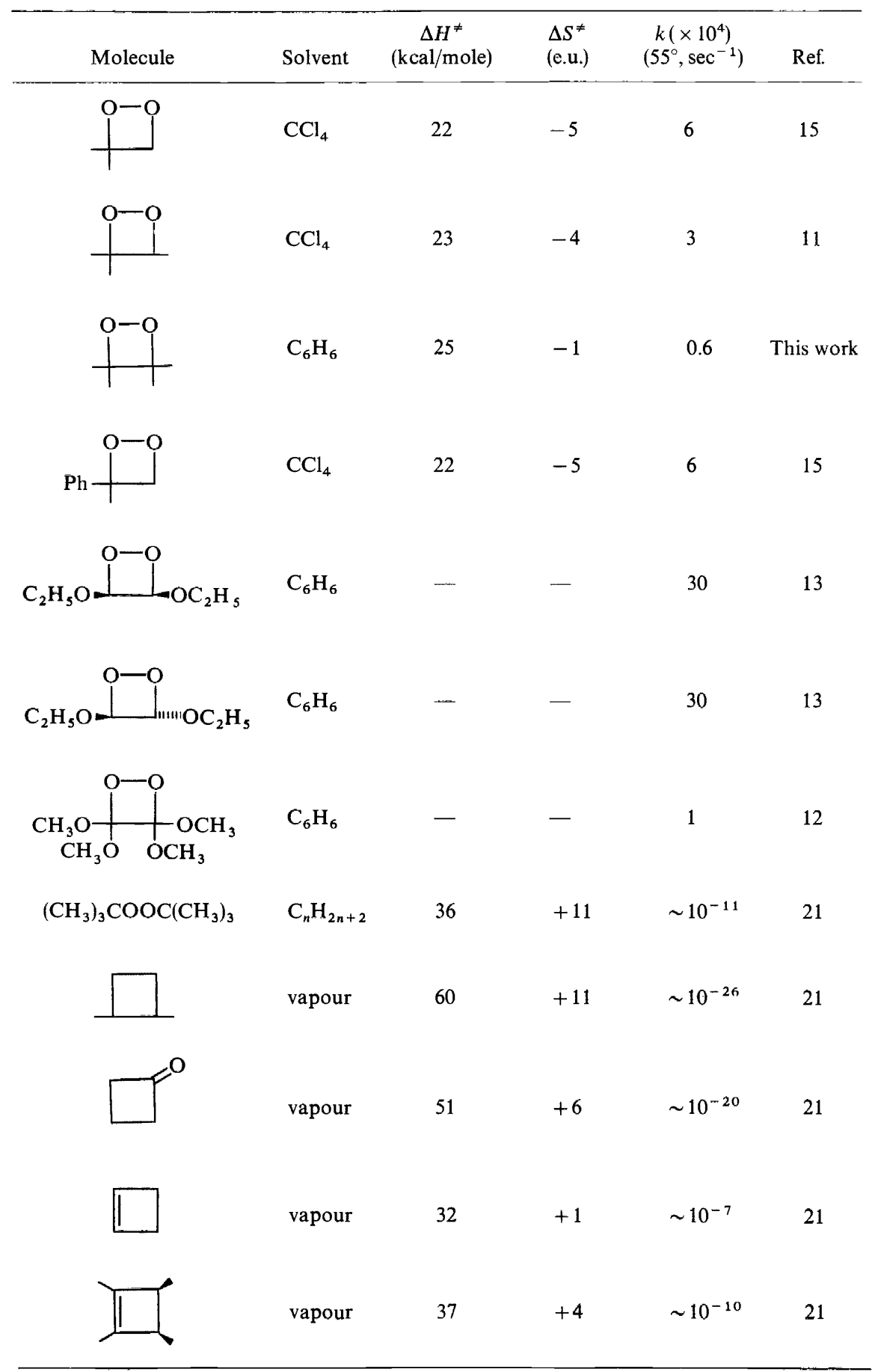




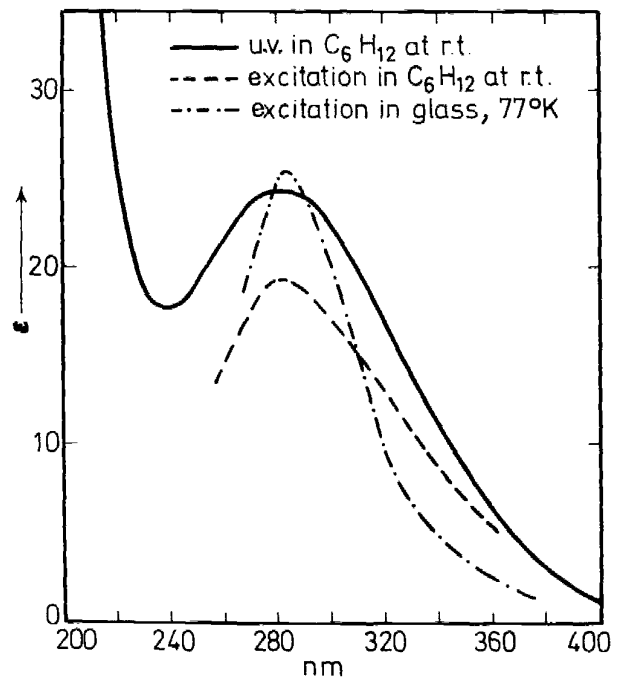

Figure 1. Absorption and excitation spectra of tetramethyl-1,2-dioxetane.

$\mathrm{V}$ is shown in Figure 1. The emission spectroscopy of $\mathrm{V}$ is even more amazing in that at room temperature or at $77^{\circ} \mathrm{K}$, photochemical excitation of $\mathrm{V}$ results in the characteristic luminescence of acetone. The excitation spectrum of the acetone luminescence is consistent with the absorption spectrum of $\mathrm{V}$ (see Figure 1). Indeed, acetone luminescence (pure fluorescence) can be produced from $V$ which is excited with light of wavelength as long as $450 \mathrm{~nm}$.<smiles>CCCCCCCCCCCCCC(=O)C(C)(C)C</smiles>

$\mathrm{V}$

Product analysis demonstrated that the photolysis of $\mathrm{V}$ in benzene at room temperature leads quantitatively to two moles of acetone (equation 6). Furthermore, the quantum yield for disappearance of $\mathrm{V}$ is 1.0. A question which immediately arises is: when singlet $\mathrm{V}$, formed by direct absorption decomposes, what are the percentages of acetone singlet $\left(\mathrm{A}_{1}\right)$ and triplet $\left(\mathrm{A}_{3}\right)$ formed? In order to answer this question we need an experimentl probe which can quantitatively distinguish $\mathrm{A}_{1}$ and $\mathrm{A}_{3}$ and which also allows extrapolation to complete trapping of $\mathrm{A}_{1}$ and $\mathrm{A}_{3}$. Such a method is available since $A_{1}$ and $A_{3}$ can be selectively 'titrated' with trans-dicyanoethylene (VI): as shown in equations 7 and 8 .

The key to this method of analysis is that VI yields completely differen 1 products with $A_{1}$ and $A_{3}$, namely the oxetane (VII) and cis-dicyanoethylen (VIII), respectively. The photoreactions given in equations 7 and 8 are believed to be well understood ${ }^{17}$. Knowledge of limiting quantum yields for formation of VII and VIII allows measurement of the limiting yields of $A_{1}$ and $\mathrm{A}_{3}$ by simple extrapolation of a plot of the yields of VII and VIII (formec 


\section{$k_{\mathrm{r}} /$}

$\left(\mathrm{CH}_{3}\right)_{2} \mathrm{CO}$

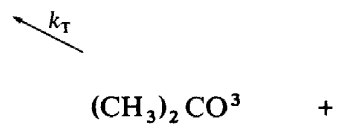<smiles>N#C/C=C\C#N</smiles>

VI<smiles>N#CC=CC#N</smiles><smiles>CC1(C)O[C@@H](C#N)C1C#N</smiles>

VII<smiles>N#C/C=C\C#N</smiles>

VI

in the presence of decomposing V) to infinite concentration of VI, i.e. at infinite concentration $k_{\mathrm{ox}}[\mathrm{VI}] \gg k_{\mathrm{F}}+k_{\mathrm{ST}}$ and $k_{\mathrm{tc}}[\mathrm{VI}] \gg k_{\mathrm{T}}$, where $k_{\mathrm{F}}$ and $k_{\mathrm{ST}}$ are the rate constants for fluorescence and intersystem crossing, the important processes involved in deactivation of $\mathrm{A}_{1}$, and $k_{\mathrm{T}}$ is the rate constant for unimolecular decay of $\mathrm{A}_{3}$ (probably determined by a mixture of intersystem crossing and $\alpha$-cleavage). The results of our study with $366 \mathrm{~nm}$ excitation are given in Table 2. Unexpectedly, photochemical excitation of $V$ results in preferential formation of $\mathrm{A}_{3}$. It should be emphasized that the approximate 4 to 1 preference for formation of $A_{3}$ over $A_{1}$ is not due to intersystem crossing of $A_{1}$, since the extrapolation to infinite concentration of VI means we have trapped every $A_{1}$ before intersystem crossing can occur.

Table 2. Production of electronically excited acetone in the direct photochemical, and triplet photosensitiżed decomposition of tetramethyl-1,2-dioxetane ${ }^{a}$

\begin{tabular}{llcc}
\hline Method & \multicolumn{1}{c}{ Excited state yield $^{\mathrm{b}}$} & Excitation wavelength \\
\hline \multirow{2}{*}{ Direct photochemical } & $\mathrm{A}_{1}$ & $\mathrm{~A}_{3}$ & \\
& 10 & 43 & $366 \mathrm{~nm}^{\mathrm{c}}$ \\
& 25 & - & $320 \mathrm{~nm}^{\mathrm{d}}$ \\
Triplet photosensitized $^{\mathrm{e}, \mathrm{f}}$ & 30 & - & $297 \mathrm{~nm}^{\mathrm{d}}$ \\
\hline
\end{tabular}

" One mole of excited acetone formed per mole of dioxetane decomposed is defined as 100 per cent, i.e. only one excited acetone is assumed to form per molecule of $\mathrm{V}$ decomposed.

- Percentage of excited acetone formed per mole of photons absorbed.

- At $6^{\circ} \mathrm{C}$ in benzene solution by titration with trans-dicyanoethylene. The $366 \mathrm{~nm}$ light is solely absorbed by the dioxetane under the applied conditions. $\Phi_{\text {disapp. }}=1.0$.

d- Determined by comparing dioxetane luminescence (pure acetone fluorescence) with that of acetone solutions of identical absorption at those wavelengths. Triplet yields not determined.

- Biacetyl sensitized at $6^{\circ} \mathrm{C}$ in benzene. See text.

' Measured by sensitization of the Type II cleavage reaction of valerophenone. See text.

Table 2 also shows the effect of excitation wavelength on the yield of $\mathrm{A}_{1}$. A steady increase in the measured efficiency of formation is observed as the exciting wavelength decreases.

It should be noted that the net efficiencies for formation of $A_{1}$ and $A_{3}$ at $366 \mathrm{~nm}$ apparently are less than unity. It is not absolutely clear whether this is due to a large experimental error or whether there is some real inefficiency in formation of electronically excited acetone. 


\section{NICHOLAS J. TURRO AND PETER LECHTKEN}

Dr Richard Hautala suggested an interesting method to test for an intermediate preceding the acetone fluorescence derived from direct excitation of $\mathrm{V}$. He reasoned that the sensitive and precise method of single photon counting was eminently suited to detect such an intermediate, since the rise time of directly excited acetone fluorescence could be determined and compared to the rise time of acetone fluorescence derived from photoexcitation of V. Indeed, the two rise times were found to be identical with an experimental precision of the order of $0.1 \times 10^{-9} \mathrm{sec}$ ! We interpret this result to require that no intermediate of lifetime greater than $10^{-10}$ sec precedes singlet acetone formation from singlet $\mathrm{V}$, since such an intermediate would have caused a delay in the rise time of acetone fluorescence. This result, of course. is consistent with the notion, mentioned earlier, that the electronically excited $\mathrm{O}-\mathrm{O}$ bond is probably cleaved within a few vibrational periods.

\section{PHOTOSENSITIZED DECOMPOSITION OF TETRAMETHYL-1,2-DIOXETANE: AN 'ANTI-STOKES' TRIPLET EXCITATION TRANSFER}

We have investigated the biacetyl photosensitized decomposition of $\mathrm{V}$. It was immediately obvious that the phosphorescence, but not the fluorescence, of biacetyl is strongly quenched by $\mathrm{V}\left(k_{\mathrm{q}}^{\mathrm{p}} \sim 10^{7} \mathrm{M}^{-1} \mathrm{sec}^{-1}\right)$. Are electronically excited states of $\mathrm{V}$ and/or acetone produced by this quenching? The answer is resoundingly positive, since sensitization of the decomposition of $\mathrm{V}$ by biacetyl triplets in the presence of valerophenone results in efficient sensitized Type II cleavage of the latter molecule. We calculate the efficiency of formation of valerophenone triplets to be $\sim 50$ per cent, based on an analysis of the data in terms of known kinetic schemes and an observed 30 per cent chemical yield of acetophenone!

Since the triplet energy of biacetyl is about $56 \mathrm{kcal} / \mathrm{mole}$ while that of valerophenone is $72 \mathrm{kcal} / \mathrm{mole}$, sensitization of formation of valerophenone triplets by biacetyl triplets constitutes a formal example of highly endothermic 'anti-Stokes' triplet excitation transfer.

It thus seems that equation 9 is appropriate to describe the result of the interaction of biacetyl and $\mathrm{V}$. The exothermicity of cleavage of $\mathrm{V}$ to two

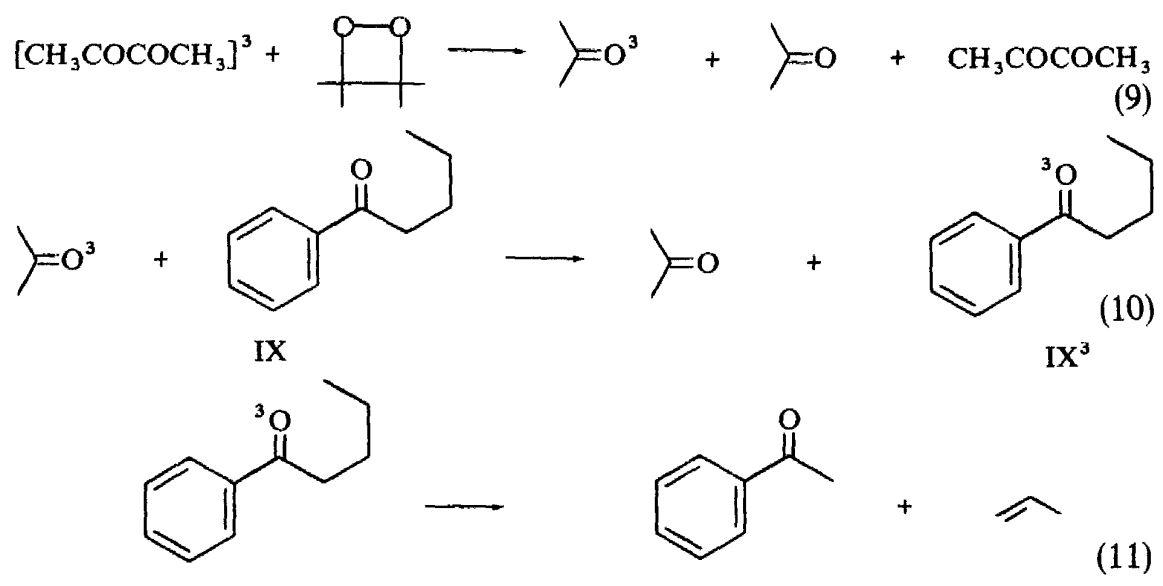


acetones $(\triangle H \sim-100 \mathrm{kcal} / \mathrm{mole})$ plus the triplet energy of biacetyl $\left(E_{3} \sim 56\right.$ $\mathrm{kcal} / \mathrm{mole}$ ) makes the formation of two acetone triplets, equation 12 , a formal possibility. However, triplet triplet annihilation and 'cage quenching' by biacetyl might reduce the efficiency of formation of 'free' acetone triplet. In this regard, it is interesting to note that the biacetyl which has sensitized the

$$
\left[\mathrm{CH}_{3} \mathrm{COCOCH}_{3}\right]^{3}+\mathrm{V} \stackrel{?}{\rightarrow} 2>=\mathrm{O}^{3}+\mathrm{CH}_{3} \mathrm{COCOCH}_{3}
$$

deccmposition of a molecule of $\mathrm{V}$ does not efficiently quench the triplet acetone molecule which is formed. Perhaps this indicates a long range quenching or a 'backside' displacement of the triplet acetone leaving group!

The efficient quenching of biacetyl triplets by $\mathrm{V}$ reminds us of the quenching of singlet states by strained molecules such as quadricyclane ${ }^{18}$ and hexamethyl dewar benzene ${ }^{19}$. However, our studies have not progressed sufficiently for us to decide upon the details of the quenching mechanism.

We should point out, however, that Wilson and Schaap ${ }^{20}$ have proposed that triplet anthracenes sensitize the decomposition of cis-diethoxy-1,2dioxetane, in order to explain the observation that oxygen 'protects' the dioxetane from an apparent induced decomposition in the presence of anthracenes.

The results reported here are quite preliminary and many studies remain to be done. Two very interesting types of experiments suggest themselves: (a) generation of 'blue light' (or electronic excitation corresponding to absorption of blue light) by use of red light excitation (equations 13 and 14) and (b) a quantum chain mechanism (with equation 15 as a possible propagation step).

$$
\begin{aligned}
& \text { sens }+ \text { 'red light' } \rightarrow \text { sens } \star \\
& \left.\left.\operatorname{sens}^{\star}+\quad \mathrm{V} \rightarrow\right\rangle=\mathrm{O}^{\star}+\right\rangle=\mathrm{O} \\
& \left.\left.\eta \mathrm{O}^{\star}+\mathrm{V} \rightarrow 2\right\rangle=\mathrm{O}^{\star}+\right\rangle=\mathrm{O}
\end{aligned}
$$

\section{THERMAL DECOMPOSITION OF TETRAMETHYL-1,2-DIOXETANE}

As expected, heating of $\mathrm{V}$ in a variety of solvents results in quantitative formation of two moles of acetone (equation 16). Kopecky and Mumford ${ }^{11}$ had reported earlier that trimethyl-1,2-dioxetane is chemiluminescent. Other<smiles>CC(C)=O</smiles>

examples of chemiluminescence concomitant with dioxetane decomposition have been observed ${ }^{12,14-16,20}$. White demonstrated that trimethyl-1,2- 
dioxetane could sensitize the triplet reactions of a number of acceptors ${ }^{22}$, with net efficiencies of up to about five per cent. Wilson and Schaap ${ }^{20}$ suggested that the dioxetane $\mathrm{X}$ yields ethyl formate singlets in high, possibly quantitative yield. Güsten and Ullman ${ }^{23}$ proposed that III is the active species in an oxalate-peroxide sensitized reaction, with net reaction efficiencies approaching five per cent in favourable cases. Chemiluminescence from XI and XII have been observed during their thermolysis.<smiles>CCO[C@H]1OO[C@H]1OCC</smiles>

$\mathrm{X}$<smiles>COC1(OC)OOC1(OC)OC</smiles>

XI<smiles>CC(C)(C)[C@H]1OOC1=O</smiles>

XII

These results leave little doubt that electronically excited states are produced upon decomposition of 1,2-dioxetanes. However, the precise nature of the electronically excited species and their mechanism(s) of formation have not been defined. Let us now consider how the mechanism of decomposition of $\mathrm{V}$ was elucidated.

It has already been noted that the reactions of singlet and triplet acetone with trans-dicyanoethylene yield the oxetane VII and cis-dicyanoethylene VIII, respectively, as the exclusive products ${ }^{24}$. It is possible to titrate simultaneously $\mathrm{A}_{1}$ and $\mathrm{A}_{3}$ with trans-dicyanoethylene as they are produced from the thermolysis of $\mathrm{V}$. The limiting yields ${ }^{25}$ of $\mathrm{A}_{1}$ and $\mathrm{A}_{3}$ from thermolysis of $\mathrm{V}$ are reported in Table 3. We are immediately confronted with the rather startling result that, based on titration with VI, the thermolysis of V yields $\mathrm{A}_{1}$ in less than one per cent while the yield of $\mathrm{A}_{3}$ is about 50 per cent! An unexpected result of this type requires independent and convincing confirmation before it can be considered as valid. However (Table 3), the same yields of $A_{1}$ and $A_{3}$ were measured, within experimental error, (1) by measurement of the chemiluminescence (pure acetone fluorescence) of V; (2) by sensitization of biacetyl fluorescence and phosphorescence; (3) by chemical titration with cis-diethoxyethylene. Thus, the evidence is quite compelling that $\mathrm{V}$ has a preference for decomposing into $A_{3}$ rather than $A_{1}$ (Figure 2).

We were able to show beyond any reasonable doubt that acetone singlets, rather than some other reactive species (like, say, the dioxetane itself), attack

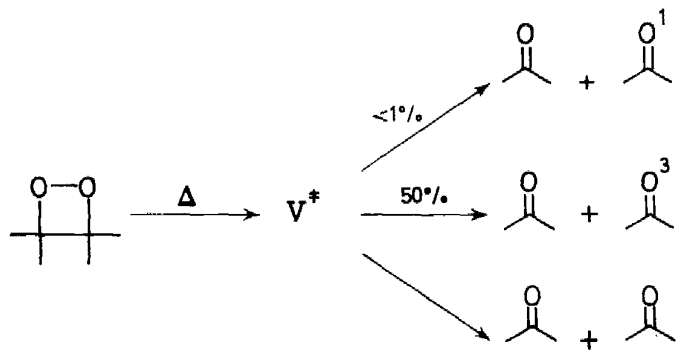

Figure 2. Thermolysis of tetramethyl-1,2-dioxetane. 
Table 3. Production of electronically excited acetone from the thermolysis of tetramethyl-1,2-dioxetane ${ }^{\mathrm{a}}$

\begin{tabular}{|c|c|c|c|c|c|c|c|}
\hline \multirow[b]{2}{*}{ Method } & \multicolumn{3}{|c|}{$\Phi(\text { Chemical })^{c} \%$} & \multicolumn{2}{|c|}{$\Phi(\text { Photo })^{\mathrm{d}} \%$} & \multicolumn{2}{|c|}{$\Phi\left(\mathrm{A}^{\star}\right)^{\mathrm{e}} \%$} \\
\hline & {$[\text { Dioxetane }]^{\mathrm{b}}$} & Oxetane & Isomerization & Oxetane & Isomerization & Singlet & Triplet \\
\hline Titration with VI & $1.07 \mathrm{M}$ & 0.02 & 5 & 8 & 10 & 0.3 & 50 \\
\hline Absolute fluorescence actinometry & $0.1 \mathrm{M}$ & - & - & - & - & 0.2 & - \\
\hline Titration with biacetyl & $0.02 \mathrm{M}$ & - & - & - & - & 0.8 & 50 \\
\hline
\end{tabular}

- Thermal decomposition of $\mathrm{V}$ at $70^{\circ} \mathrm{C}$ in benzene. It follows first order kinetics $\left(k=4.05 \times 10^{-4} \mathrm{sec}^{-1}\right.$ at $\left.71^{\circ}\right)$. The same rate is found for decomposition of $\mathrm{V}$ and disappearance of chemiluminescence at the maximum $404 \mathrm{~nm}$. Error limits are estimated to be of the order of \pm 50 per cent.

b Actual runs. Variation of the concentration ratio [Dioxetane]/[quencher] from 2:1 to 1:2 had no significant effect. Averages: 0.2 per cent singlet, 50 per cent triplet per mole of dioxetane decomposed.

- Percentage product formation per mole of dioxetane decomposed. Singlets form oxetanes, triplets give rise to isomerization.

Limiting quantum yields. See ref. 24 for details.

- $\Phi$ excited $=\Phi$ chem $/ \Phi$ photo.

( Absolute actinometry, using ferrioxalate. See J. N. Demas, G. A. Crosby, J. Phys. Chem. 75, 991 (1971)

- Extrapolated to infinite concentration of biacetyl. 
$t$-DCE. This was done by demonstrating that Stern-Volmer quenching of the chemiluminescence of $\mathrm{V}$ by $t$-DCE (benzene solution) yields the same slope $\left(k_{\mathrm{g}} \tau\right)$ as that obtained from quenching of acetone fluorescence by $t-\mathrm{DCE}^{25}$.

Incidental to this study we noticed that high concentration of $\mathrm{V}$ decreases the net yield of $A_{3}$, indicating that $V$ is a quencher of $A_{3}$. Consistent with this possibility is the observation that degassed solutions show less chemiluminescence than aerated solutions. We interpret this result as follows: since oxygen is known to be an efficient quencher of $A_{3}$ but not $A_{1}$, oxygen protects $V$ against sensitized decomposition by $A_{3}$ (which apparently does not generate $A_{1}$ ), thereby allowing more molecules of $\mathrm{V}$ to form $\mathrm{A}_{1}$ (the state responsible for chemiluminescence). This result is the basis of our earlier conclusion that quenching of biacetyl triplets by $\mathrm{V}$ does not generate $A_{1}$.

In addition to the remarkably efficient and selective formation of $\mathrm{A}_{3}$ relative to $A_{1}$, we wish to point out that the blue (acetone fluorescence) chemiluminescence is a 'red herring' with respect to the major method for excited state production from $\mathrm{V}$. This shows the hazards of making mechanistic conclusions solely on the basis of low efficiency chemiluminescence. Finally, $\mathrm{V}$ is a 'self quencher' of chemielectronic production of $\mathrm{A}_{3}$, while dissolved oxygen is a 'promoter' of chemiluminescence. We conclude that low concentrations of $\mathrm{V}$ in the absence of oxygen (i.e. under conditions that chemiluminescence is decreased) are most favourable for efficient production of chemically useful excited states (triplets) from V.

\section{ACTIVATION PARAMETERS FOR THE DECOMPOSITION OF TETRAMETHYL-1,2-DIOXETANE. SOLVENT EFFECTS}

In order to gain further insight concerning the mechanism of thermolysis of $\mathrm{V}$, the activation parameters for fragmentation were measured. Since the rate of decomposition of $\mathrm{V}$ is directly proportional to the rate of formation of acetone singlets, which is in turn directly proportional to the chemiluminescence intensity, therefore the kinetics for decomposition of $\mathrm{V}$ are easily followed by the sensitive and precise method of fluorimetry. The activation parameters for decomposition of $\mathrm{V}$ in several solvents are listed in Table 4. There

Table 4. Solvent dependence of the activation parameters for thermal decomposition of tetramethyl-1,2-dioxetane

\begin{tabular}{lccc}
\hline \multicolumn{1}{c}{ Solvent } & $\begin{array}{c}\Delta H^{\neq} \\
(\mathrm{kcal} / \mathrm{mole})\end{array}$ & $\begin{array}{c}\Delta S^{\neq} \\
(\mathrm{e} . \mathrm{u} .)\end{array}$ & $\begin{array}{c}k\left(\times 10^{4}\right) \\
\left(55^{\circ}, \mathrm{sec}^{-1}\right)\end{array}$ \\
\hline Acetonitrile & 30 & +11 & 0.4 \\
1,3-Cyclooctadiene & 27 & +5 & 0.5 \\
trans-2,4-Hexadiene & 27 & +5 & 0.5 \\
2,5-Dimethylhexadiene & 26 & +2 & 0.6 \\
4-Bromotoluene & 26 & +2 & 0.6 \\
Cyclohexane & 25 & -1 & 0.7 \\
Benzene & 25 & -1 & 0.7 \\
Cyclohexene & 23 & -8 & 1.0 \\
Isopropanol & 20 & -15 & 1.1 \\
Methanol & 13 & -34 & 8.0 \\
\hline
\end{tabular}




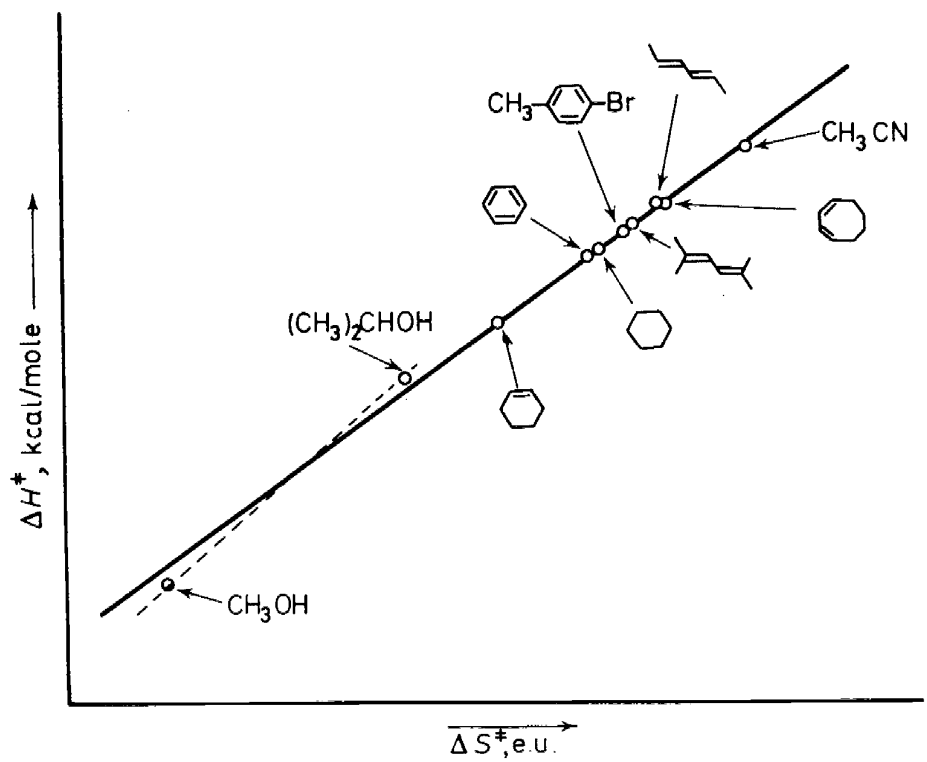

Figure 3. Correlation of $\Delta H^{\ddagger}$ and $\Delta S^{\neq}$for the thermolysis of tetramethyl-1,2-dioxetane in various solvents. The two alcohols studied appear to fall on a separate line.

is a rather large spread in the values of $\Delta H^{\ddagger}$ and $\Delta S^{\neq}$in different solvents. However, a rather good straight line is achieved when $\Delta H^{\ddagger}$ is plotted versus $\Delta S^{\neq}$(Figure 3). This plot is thus evidence for an isokinetic relationship ${ }^{26}$, i.e. $\Delta H^{\neq}=\beta \Delta S^{\neq}$, where $\beta$ is / the isokinetic temperature, equal to $86^{\circ}$ in this case. The occurrence of an isokinetic relationship is consistent with one major interaction mechanism in the thermolysis of $\mathrm{V}^{26}$. Alcohols (Figure 3) do not adhere strictly to the relationship, however.

The integrated chemiluminescence intensity $\Phi_{\mathrm{CL}}$ is proportional to the yield of $A_{1}$ in the thermolysis of V. Significantly a plot of $\ln \Phi_{C L}$ versus the activation energy for decomposition of $\mathrm{V}$ in different solvents yields a straight line (Table 5). This result suggests that the mechanism involving formation of $A_{1}$ is relited to the major decomposition path.

The work of Richardson and $\mathrm{O}^{\prime} \mathrm{Neal}^{15}$ has shown that the activation parameters for the decomposition of the dioxetanes XIII and XIV in carbon tetrachloride are experimentally indistinguishable $\left(E_{\mathrm{a}}=23.0 \mathrm{kcal} / \mathrm{mole}\right.$,

Table 5. Solvent dependence of chemiluinescence from tetramethyl-1,2-dioxetane

\begin{tabular}{lcc}
\hline Solvent & $\begin{array}{c}\Delta H^{\neq} \\
(\mathrm{kcal} / \mathrm{mole})\end{array}$ & $\begin{array}{c}\Phi_{\mathrm{CL}}{ }^{\mathrm{a}} \\
\%\end{array}$ \\
\hline Acetonitrile & 30 & 0.28 \\
Benzene & 25 & 0.20 \\
Cyclohexene & 23 & 0.13 \\
Ethanol & $16^{\mathrm{b}}$ & 0.07 \\
\hline
\end{tabular}

Chemiluninescence yield determined by integration of the corrected acetone fluorescence observed during thermolysis of V. T equals $69^{\circ}$.

b Estimated from the values for methanol and isopropanol. See Table 4. 
$\Delta H^{\neq}=22.4 \mathrm{kcal} / \mathrm{mole} ; \log A=12.2, \Delta S^{\neq}=-5$ e.u.). They interpreted these data as evidence for a two-step mechanism, in which the key energetic and structural feature required to reach the transition state is breaking of the $\mathrm{O}-\mathrm{O}$ bond. In a concerted mechanism the phenyl group would be expected to interact differently from the methyl with respect to the developing carbonyl bond (as has been suggested to be the case in fragmentations of alkoxy radicals). In agreement with their premise, these authors showed that calculated activation parameters, based on a two-step mechanism with rate-determining formation of a biradical intermediate, were in good agreement with their experimental data.<smiles>CC1(C)COOC1</smiles>

XIII<smiles>CCCCCCC1(C)COO1</smiles>

XIV

\section{REACTIONS WHICH PRODUCE PRODUCTS IN AN ELECTRONICALLY EXCITED STATE OR WHICH UNDERGO A CHANGE IN ELECTRONIC STATE}

Some fundamental and thought-provoking ideas should be considered before the possible detailed mechanisms for photochemical and thermal decomposition of $\mathrm{V}$ are explored; namely, the concepts of chemical reactions which undergo a change of electronic state along the reaction profile and/or chemical reactions which produce products in electronically excited states. These ideas are shown schematically in Figure 4. In this diagram the conversion $\mathrm{R} \rightarrow \mathrm{P}^{\star}$ and $\mathrm{R}^{\star} \rightarrow \mathrm{P}^{\star}$ are changes in state which produce an electronically excited product (electronic excitation denoted by $\star$ and vibrational excitation by $\neq$ ). The conversion $R^{\star} \rightarrow P^{\star}$ is a radiationless process in which a change of electronic state must occur somewhere along the reaction coordi-

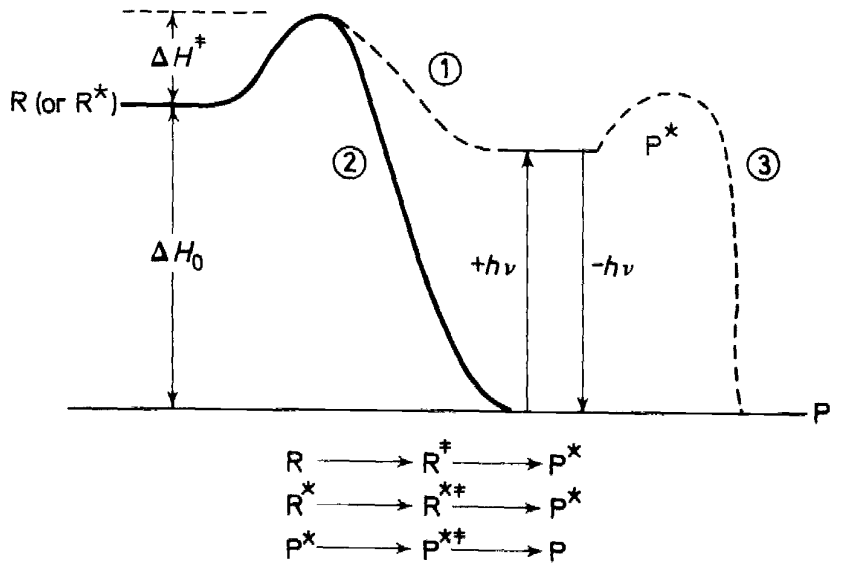

Figure 4. Schematic description of processes involving formation of products in electronically excited states. 
nate. In effect, all photoreactions involve at least one radiationless process before a final, ground state product is formed.

Radiationless electronic excitation and de-excitation are generally classified as 'physical' processes if these processes occur within the framework of the electronic states of a single molecule. Hammond ${ }^{27}$ has convincingly pointed out that such a classification is not fundamentally required. He has indicated that such a classification may violate our most deep-seated intuitive notions in certain cases such as collapse of a perpendicular ethylene to cis and trans-isomers: the physical or chemical nature of the process would depend on the structure of the starting olefin! Indeed, one can perhaps better support a radically different point of view, namely that all electronically excited states are electronic isomers of the ground state, thus all electronic state interconversions involving at least one electronically excited state are chemical in nature. This view of things would logically include radiative processes where, in absorption, the photon is a reagent and, in emission, the photon is a product. An advantage of this attitude is that organic photochemistry then broadens, in a natural way, its purview to include all reactions which interconvert electronic states, whether or not light is involved in any of the excitation and/or de-excitation processes. The 'photo' part simply means that light happens to be the most convenient general way of producing or detecting an electronically excited state. Now let us return to Figure 4. The process $R^{\star} \rightarrow P^{\star}$ might be (a) an intramolecular excited state interconversion such as $\mathrm{S}_{2} \rightarrow \mathrm{S}_{1}, \mathrm{~S}_{1} \rightarrow \mathrm{T}_{1}$, etc. or (b) an excited state interconversion such as $V^{\star} \rightarrow A_{1}+A_{0}$ or $V^{\star} \rightarrow A_{3}+A_{0}$, in which electronically excited states of a molecule different from $R$ are generated. The process $\mathrm{R} \rightarrow \mathrm{P}^{\star}$ leads to an electronically excited state from a ground state starting material. The electronically excited product is identical in all cases to the species produced by light excitation, i.e. $h v+\mathrm{P} \rightarrow \mathrm{P}^{\star}$. Furthermore, it seems sensible to try to treat analysis of the mechanism of the process $\mathrm{R} \rightarrow \mathrm{P}^{\star}$ in a manner analogous to the treatment of the $\mathrm{P}^{\star} \rightarrow \mathrm{P}^{\neq}$process. This frame of reference is easily extended to the cases in which $\mathrm{P}^{\star}$ undergoes a proreaction itself, to yield a product $\mathbf{P}^{\prime}$.

Now we also can see that chemiluminescence, the process $\mathrm{R} \rightarrow \mathrm{P}^{\star} \rightarrow \mathrm{P}+h v$, is simply a specific corollary of the more general theory of generation of products in electronically excited states.

The theory of radiationless transitions and chemical reactions can be treated under the general concept of electronic relaxation. The available theories of radiationless transitions may, therefore, provide a source of useful and refreshing ideas and language to discuss rate processes. Some of the connections between the usual manners in which an organic chemist and a spectroscopist might discuss electronic relaxation processes can be gathered from a comparison of the familiar ${ }^{28,29}$ equations 17 and 18. Instead of the usual attempts to evaluate $\Delta H^{\neq}$and $\Delta S^{\neq}$, the key conceptual quantities of transition state theory (the model of kineticists), we shift to dynamic

$$
\begin{aligned}
& \text { rate } \propto \exp \left(-\Delta H^{\neq} / R T\right) \times \exp \left(\Delta S^{\neq} / R\right) \\
& \text { rate } \propto \frac{\left\langle\psi_{i}|H| \psi_{f}\right\rangle^{2}}{\Delta E_{i f}} \sim \frac{\left\langle\phi_{i}|H| \phi_{f}\right\rangle^{2}\left\langle\chi_{i} \mid \chi_{f}\right\rangle^{2}}{\Delta E_{i f}}
\end{aligned}
$$


perturbation theory (equation 18) for consideration of conversion of electronic energy into nuclear motion (vibrational energy) as we pass from the 'transition state' $\left(\psi^{\neq}\right)$to upper vibrational states of the product $\left(\psi_{f}^{\neq}\right)$. This theory is thus essentially vibronic in nature. The important, usable concepts in equation 18 are the electronic matrix element $\left\langle\phi_{i}|H| \phi_{f}\right\rangle$, the vibrational overlap integral $\left\langle\chi_{i} \mid \chi_{f}\right\rangle$ and the energy gap between the interacting states. With the exception of the vibrational overlap integral, equation 18 is the basis for the orbital symmetry ${ }^{30,31}$ rules in which specific nuclear motions and electronic interactions are expected to be particularly favoured in concerted reactions, i.e. the 'best' electronic interactions between $\psi_{i}$ and $\psi_{f}$ are vibrationally induced. Certainly, many organic photochemists will not find equation 18 to be a comfortable and/or comprehensible theoretical framework in which to discuss rate processes. Yet we are all probably familiar enough with orbital language to commonly write down pretty pictures of overlapping lobes in order to rationalize our observations. Perhaps the important feature of equation 18 of general impact is that, in addition to the expected electronic overlap term and symmetry considerations, new possibilities for $H$ come to mind, and the initial vibrational motions which couple $\psi_{\mathrm{i}}$ and $\psi_{\mathrm{f}}$ are emphasized. We shall see in the discussion of the mechanism of decomposition of $\mathrm{V}$, that we can profitably make good use of the ideas suggested by equation 18 to infer some fascinating detail about bondbreaking processes; and gain some insight into how $\mathrm{V}$ is able effectively to store so much energy, in spite of the apparently simple electronic reorganization which could release an enormous amount of free energy.

\section{MECHANISMS FOR THE PHOTOCHEMICAL AND THERMAL DECOMPOSITION OF TETRAMETHYL-1,2-DIOXETANE}

Let us summarize the prominent features of the photochemical and thermal decomposition of $\mathrm{V}$ which must be handled by any mechanism: (a) two molecules of acetone are produced per molecule of $\mathrm{V}$ decomposed under all conditions which were studied; (b) the formation of triplet acetone is favoured over that of singlet acetone under both photochemical and thermal excitation of $\mathrm{V}$; (c) the solvent dependence of the activation parameters for thermolysis of $\mathrm{V}$ reveals an isokinetic relationship; (d) hydroxylic solvents do not adhere strictly to the isokinetic relationship; (e) the formation of electronically excited products from $\mathrm{V}$ is not completely efficient in either its thermolysis or photolysis; ( $f$ ) the activation parameters for decomposition of other 1,2dioxetanes do not depend much on structure.

First let us attack the mechanism of the thermal reaction in non-polar solvents, e.g. benzene, cyclohexane or carbon tetrachloride. The activation parameters in such solvents are $\Delta H^{\ddagger} \sim 23$ to $25 \mathrm{kcal} / \mathrm{mole}$ and $\Delta S^{\ddagger} \sim-1$ to -5 e.u. Contrast these values with those for decomposition of di-tert-butyl peroxide (equation 19) and fragmentation of a cyclobutane (equation 20). The lower enthalpy of activation of $\mathrm{V}$ relative to acyclic alkyl peroxides can be taken care of in any mechanism by invoking ring strain, which is estimated as about $26 \mathrm{kcal} / \mathrm{mole}^{15}$. However, the low, slightly negative, value of $\Delta S^{\neq}$for $\mathrm{V}$ and other dioxetanes (Table 1) suggests that either the 


$$
\begin{aligned}
& \left(\mathrm{CH}_{3}\right)_{3} \mathrm{CO}-\mathrm{OC}\left(\mathrm{CH}_{3}\right)_{3} \stackrel{\Delta}{\longrightarrow} 2\left(\mathrm{CH}_{3}\right)_{3} \mathrm{CO} \text {. } \\
& \Delta H^{\ddagger} \sim 35 \mathrm{kcal} / \mathrm{mole} \\
& \Delta S^{\ddagger} \sim+10 \text { e.u. } \\
& \square \longrightarrow \Delta+11 \\
& \Delta H^{\neq} \sim 60 \mathrm{kcal} / \mathrm{mole} \\
& \Delta S^{\neq} \sim+10 \text { e.u. }
\end{aligned}
$$

starting material has not gained a substantial increase in flexibility, or has a low probability in reaching to the transition state, or that some ordering of solvent is required. The latter seems unlikely to be important in cyclohexane. Several specific proposals to explain the $\Delta S^{\neq}$values are (a) the $\mathrm{O}-\mathrm{O}$ bond breaks but reforms, thereby achieving the transition state, but not proceeding on to product; (b) achievement of the transition state requires a change in electronic state ${ }^{30}$, i.e. a singlet to triplet conversion, or a conversion of a massive amount of chemical energy into vibration energy, such as formation of two vibrationally excited acetone molecules; (c) specific restrictive molecular motions are required to achieve the transition state.

As we have seen, there is convincing evidence that the $\mathrm{O}-\mathrm{O}$ bond is nearly fully broken in the transition state, i.e. the transition state is 'biradical like' in character, since the activation parameters for thermolysis are structureinsensitive and because a biradical model for the transition state allows accurate calculation of the activation parameters ${ }^{15}$. What about the possibility then, that the biradical forms but then recollapses to dioxetane? We cannot think of any rigorous way to rule this possibility out; however, the reverse reaction should have an activation energy of about $8-10 \mathrm{kcal} / \mathrm{mole}^{15}$. The cleavage of the carbon-carbon bond should be quite facile from the biradical, since $E_{\mathrm{a}}$ for fragmentation of a methyl group from the tert-butoxy radical is only $-15 \mathrm{kcal} / \mathrm{mole}^{21}$. Since the activation energy for $\beta$-cleavage of butoxy radicals decreases as the stabilization of the leaving group increases ${ }^{31}$, the biradical XVII may well have an activation energy for cleavage much less than $8 \mathrm{kcal} / \mathrm{mole}$. Furthermore, fragmentation should be increased in rate in a solvent like cyclohexene, if we use tert-butoxy radicals as a model, since Walling and Wagner ${ }^{32}$ found that cyclohexene had a profound effect of enhancing cleavage of alkoxy radicals over other modes of decomposition.

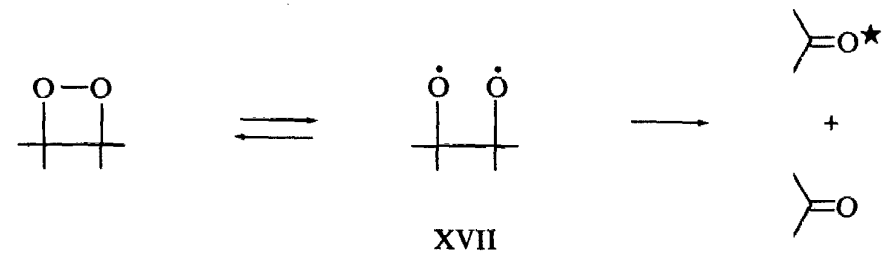

The second explanation, i.e. that a singlet-triplet conversion is required in going to the transition state, is particularly intriguing. The reaction $\mathrm{N}_{2} \mathrm{O} \rightarrow$ $\mathrm{N}_{2}+\mathrm{O}$ is believed to be an example of such a non-adiabatic process ${ }^{33}$. 
However, no well documented examples of organic reactions which follow such a reaction surface are known, although cis-trans isomerization of certain ethylenes was once thought to conform to this model ${ }^{33}$. In any case, the lack of a heavy atom effect (4-bromotoluene falls on the isokinetic line) and the rather large positive value of $\Delta S^{\neq}$in acetonitrile suggests that the spin flip required to obtain the major product, acetone triplet, occurs after the transition state is achieved, for all intents and purposes.

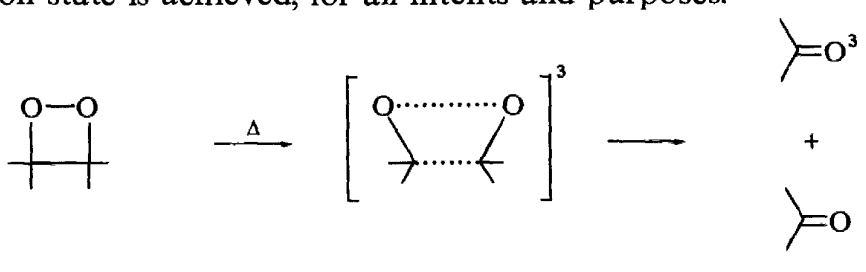

The possibility of a conversion of a massive amount of electronic energy into vibrational energy seems intuitively unreasonable, i.e. a violation of the chemical equivalent of the Franck-Condon principle (the nuclear factor in equation 18 is very small). However, we must admit that our results suggest that some fraction of V may, in fact, follow such a path.

We shall now show that the third mechanism, in which specific molecular motions are required to achieve the transition state, is consistent with the observed $\Delta S^{\neq}$values, and furthermore, has the ability to correlate the other observations quite satisfactorily.

The most obvious types of nuclear motion, which might be more restrictive in $\mathrm{V}^{\neq}$than in the ground state, are those in which pendant groups are caused to interfere with one another in achieving $\mathrm{V}^{\neq}$, thereby reducing vibrational and rotational freedom. Arguments based on this attitude have severe difficulties when confronted with the data on activation parameters given in Table 1. Certainly, if eclipsing effects were operating to cause the low activation entropies, we would expect a wide variation in $\Delta S^{\neq}$which should decrease with increasing encumbrances due to pendant groups on the carbon atoms. In fact, the most hindered dioxetane for which a value of $\Delta S^{\neq}$is available, namely $\mathrm{V}$, has the highest value of $\Delta S^{\neq}$. Note, however, the increase in $\Delta H^{\ddagger}$ as one proceeds from the 3,3-dimethyl (XIII) to trimethyl (XIX) to tetramethyl dioxetanes. If this effect is ascribed to destabilizing interactions between pendant groups in the transition state, there cannot be much entropy loss associated with the group interactions. Note, moreover, that in a 'classic' case of a biradical fragmentation, namely, fragmentation of 1,2-dimethylcyclobutane [into two molecules of propylene (Table 1)], the values of $\Delta S^{\neq}$ are highly positive $(+11$ e.u.)! Furthermore, cis-1,2,3,4-tetramethylcyclobutene (XX) provides a good model for what to expect when two methyl groups are compelled to rotate as a transition state is approached. Notice that for XX relative to cyclobutene, $\Delta H^{\neq}$increases (by $5 \mathrm{kcal} / \mathrm{mole}$ ) and $\Delta S^{\neq}$ increases (by 3 e.u.) while for XIII relative to $\mathrm{V}, \Delta H^{\neq}$increases (by $4 \mathrm{kcal} / \mathrm{mole}$ ) and $\Delta S^{*}$ increases (by 4 e.u.)! Since the thermal ring opening of XX is conrotatory, the methyl groups have a very specific motion which achieves the transition state. The disrotatory motions are not productive in forming the lowest energy transition state. The above discussion suggests to us that a close relationship may exist between the 'classical' concerted ring opening of cyclo- 
butenes and the ring opening of dioxetanes. Indeed, in the one example of solvent effects on the activation parameters for ring opening of cyclobutenes, we have been able to locate in the literature ${ }^{21}$, an apparent isokinetic relationship holds! Let us now follow up this line of thinking a bit more closely.

Consider the cleavage of the $\mathrm{O}-\mathrm{O}$ bond of $\mathrm{V}$ as being nearly complete in the transition state $\mathrm{V}^{\neq}$and then consider the final product, triplet acetone (equation 23). Notice that a $90^{\circ}$ rotation of the bonding lobe on the left hand

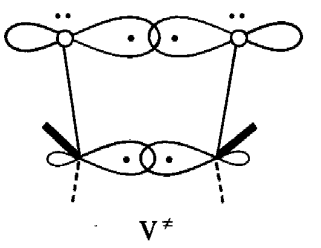

$\mathbf{V}^{\neq}$

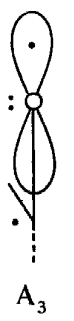

$\mathbf{A}_{3}$

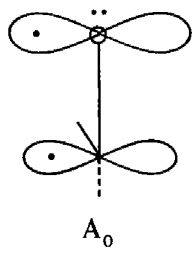

oxygen generates the final $\mathrm{n}, \pi^{\star}$ state. Furthermore, this electronic motion is formally analogous to that required for maximal spin orhital coupling in a molecule so that the normal prohibition to spin interconversion is expected to be substantially lowered ${ }^{34}$ !

That this should be the case can be easily demonstrated to anyone who believes that ${ }^{1} \mathrm{n}, \pi^{\star} \rightleftarrows{ }^{3} \pi, \pi^{\star}$ spin interconversions are allowed relative to ${ }^{1} \mathrm{n} . \pi^{\star} \rightleftarrows{ }^{3} \mathrm{n}, \pi^{\star}$ and ${ }^{1} \pi, \pi^{\star} \rightleftarrows{ }^{3} \pi, \pi^{\star}$ interconversions. Equation 23 shows pictorially how the formal mathematical operation of the spin orbital coupling operator ${ }^{34}$ corresponds to the motion of a $p$-like orbital through $90^{\circ}$, and is thereby theoretically connected to the type of motion which converts $V^{\neq}$into $A_{3}$ and $A_{0}$ ! We note that it is the initial nuclear motions which probably are important here, in the same way that one must suppose that initial nuclear motions dominate the rates of formation of transition states for photoreactions which adhere to orbital symmetry ${ }^{30,31}$ rules, e.g. electrocyclic ring openings and closures. Thus, an idea which has long been part and parcel of the theory of state interconversions used by molecular electronic spectroscopists ${ }^{34}$ may now be applied in a very intriguing way to help understand the mechanism of decomposition of an organic molecule, i.e. the conversion of $\mathrm{V}^{\neq}$to $\mathrm{A}_{3}+\mathrm{A}_{1}$ is a vibrationally induced intersystem crossing.

Carrying this idea a bit further, we can understand the wide range of $\Delta H^{\neq}$ and $\Delta S^{\neq}$values on the basis of a mechanism which involves a transition state which is biradical-like in character, but which requires a 'twist' motion of the fragmenting sigma orbital of the $\mathrm{O}-\mathrm{O}$ bond. Let us consider the values of $\Delta H^{\neq}$and $\Delta S^{\neq}$in cyclohexane, and assuming the solvent effect to be negligible here, the $\Delta H^{\neq}$value $(25 \mathrm{kcal} / \mathrm{mole})$ represents a value for breaking the $\mathrm{O}-\mathrm{O}$ bond and the $\Delta S^{\neq}$value ( -1 e.u.) represents a loosening of molecular motions as the $\mathrm{O}-\mathrm{O}$ bond breaks (increase in entropy) but also a specific kind of motion as shown in equation 23 (decrease in entropy) thereby leading to a nearly zero value for $\Delta S^{\neq}$. The breaking of the $\mathrm{O}-\mathrm{O}$ bond can be assisted by charge transfer stabilization of the transition state by the solvent (cyclohexene, $\Delta H^{\neq}=23 \mathrm{kcal} / \mathrm{mole}$ ). This is quite analogous to the effect observed by Walling and Wagner ${ }^{32}$ on the fragmentation of alkoxy radicals. These authors 
found that cyclohexene solvent has a marked effect which strongly favoured $\beta$ scission (equation 24) over hydrogen abstraction. There is an entropy price to be paid, in this mechanism, and we note that indeed $\Delta S^{\neq}$becomes more negative $(-8$ e.u.) than the value in cyclohexane. Hydrogen bonding might also be expected to assist cleavage of the $\mathrm{O}-\mathrm{O}$ bond in analogy to the results of Walling and Wagner ${ }^{32}$. Indeed, $\Delta H^{\neq}$is much lower in isopropanol ( $20 \mathrm{kcal} /$ mole) and drops further (to $12 \mathrm{kcal} / \mathrm{mole}$ ) when the more acidic, less hindered molecule, methanol is solvent. The entropy price paid here is mainly due to tying up the solvent in specific orientations and is more costly $\left(\Delta S^{\neq}=-15\right.$ e.u. and -34 e.u., for isopropanol and methanol, respectively).<smiles>[R]C([R])([R])O[Si]</smiles><smiles>[R]C([R])([Si])C([R])([R])O[Si]</smiles>

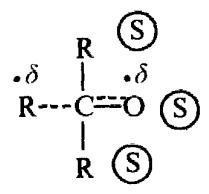

One may now ask the question, is there any 'linear-type' of cleavage of the $\mathrm{O}-\mathrm{O}$ bond? We have no good arguments for its specific occurrence, but perhaps the fragmentation of $V$ into singlet states $\left(A_{1}+A_{0}\right.$ or $\left.2 A\right)$ involves such a cleavage. It is interesting to note, in this regard, that as the activation energy rises, the relative yield of $A_{1}+A_{0}$ increases (Table 5).

With respect to the photochemical decomposition of $\mathrm{V}$, we do not have sufficient data for a detailed mechanistic picture. It seems reasonable, however, to suppose that the $\mathrm{O}-\mathrm{O}$ bond would be cleaved easily in the excited states of $\mathrm{V}$. The factors determining ratio of singlet and triplet yields are a bit more difficult to assess now, since they may reflect the rate of intersystem crossing of $\mathrm{V}\left(\mathrm{S}_{1}\right)$ rather than the rates of direct partitioning of $\mathrm{V}\left(\mathrm{S}_{1}\right)$ into $A_{1}$ and $A_{3}$. The wavelength dependence is consistent with either view, if we hypothesize that higher excitation energy favours $V\left(S_{1}\right) \rightarrow A_{1}+A_{0}$, with respect to intersystem crossing which eventuates in $V\left(T_{1}\right) \rightarrow A_{3}+A_{0}$.

The faster rate of cleavage of $T_{1}$ relative to $S_{1}$ has a possible analogy in the observation that $\mathrm{n}, \pi^{\star}$ triplets of alkanones undergo $\alpha$-cleavage at a much faster rate than $n, \pi \star$ singlets $^{17}$.

\section{A SEARCH FOR CATALYSIS OF FRAGMENTATION OF V BY ENERGY ACCEPTORS}

One of the possible reasons for the remarkable stability of dioxetanes has been put forth in the previous section. Let us now consider the fascinating 
question: can an electronic or vibrational energy acceptor 'catalyse' the fragmentation of dioxetanes by (a) diminishing the problem of conversion of substantial amounts of chemical energy into vibrational energy, i.e. equation 26 or (b) by providing a path for a 'non-classical' electronic energy from a

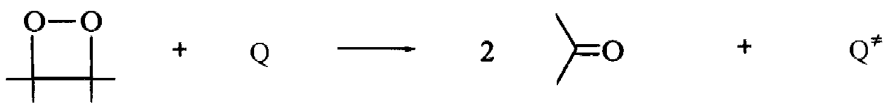

ground state donor to produce an electronically excited acceptor, i.e. equation 27.

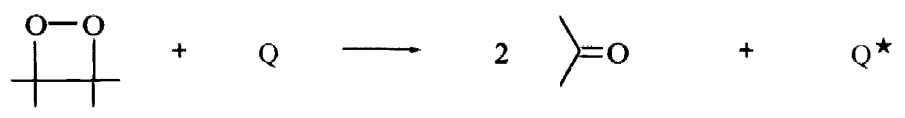

Both these mechanisms, if they are elementary reactions, will require some electronic coupling or complexing for reaction to occur efficiently. Thus, the rate of fragmentation of $\mathrm{V}$ may suffer from an increase in $\Delta G^{\neq}$due to a more negative $\Delta S^{\neq}$. We should thus search for catalysis by analysing $\Delta H^{\neq}$.

Before doing so, let us point out that Rauhut ${ }^{8,37}$ suggested some time ago that the decomposition of III might be catalysed by certain aromatic compounds (e.g. anthracenes) in order to explain enhanced decomposition rates in some chemiluminescent reactions. $\mathrm{He}^{8}$ also suggested that the acceptor is behaving as an electron donor in these catalyses so that the ionization potential of the acceptor might be important in determining the effectiveness of a catalyst. Mazur and Foote ${ }^{12}$ have reported the apparent catalysis on tetramethoxy dioxetane by zinc tetraphenylporphine. Kopecky and Mumford $^{11}$ found that $0.2 \mathrm{M}$ biacetyl increases the rate of decomposition of trimethyl-1,2-dioxetane by a factor of nearly two. However, Wilson and Schaap ${ }^{20}$ have shown that enhanced rates of decomposition may be due to energy acceptors, relaying their newly acquired electronic excitation energy to a ground state dioxetane, thereby causing its 'sensitized' decomposition. Thus, the role of any real 'catalysis' by added energy acceptors is not fully established.

We have measured the activation parameters for thermal decomposition of benzene solutions $\mathrm{V}$ in the presence of energy acceptors (Table 6). In each case, the fluorescence of the acceptor ${ }^{20,38}$ was excited by decomposing V.

Table 6. Activation parameters for thermolysis of benzene solutions of tetramethyl-1,2-dioxetane in the presence of energy acceptors

\begin{tabular}{|c|c|c|c|c|c|}
\hline Acceptor $^{\mathrm{a}}$ & $\left(\mathrm{kcal} / \mathrm{mole}^{-1}\right)$ & $\left(\begin{array}{c}\Delta S^{\neq} \\
(\mathrm{e} .)\end{array}\right.$ & $\begin{array}{c}\left.k\left(\times 10^{4}\right)_{1}\right) \\
\left(60^{\circ} \mathrm{C}, \sec ^{1}\right)\end{array}$ & $\Phi_{\mathrm{Cl}}^{\mathrm{rel}^{\mathrm{b}}}$ & $\Phi_{\mathrm{ST}}^{\mathrm{c}}$ \\
\hline None & 25 & -1 & 1.3 & & \\
\hline Rubrene & 26 & +0.5 & 1.0 & 0.4 & 0.01 \\
\hline 9,10-Dimethyl-A & 31 & +16 & 0.5 & 1.0 & 0.25 \\
\hline 9,10-Dibromo-A & 28 & +8 & 0.6 & 120 & 0.9 \\
\hline 9,10-Dichloro-A & 27 & +4 & 1.1 & 4.3 & 0.45 \\
\hline 9,10-Diphenyl-A & 20 & -16 & 2.2 & 0.6 & 0.16 \\
\hline
\end{tabular}

\footnotetext{
- A denotes anthracene; $0.01 \mathrm{M}$ in benzene, aerated solutions. Ratio acceptor/dioxetane $=1: 2$.

' Relative chemiluminescence yields, corrected for the relative fluorescence quantum yields under the applied conditions $\left(69^{\circ}\right.$ in benzene).
} 


\section{NICHOLAS J. TURRO AND PETER LECHTKEN}

Triplet to singlet energy transfer (equation 28) has been proposed as the mechanism for excitation of acceptor fluorescence. The data in Table 6 are not easily correlated by such a thesis. Thus, 9,10-dibromoanthracene is ex-

$$
\begin{gathered}
=\mathrm{O}^{3}+\mathrm{Q} \longrightarrow \mathrm{O}^{1}+\mathrm{Q}^{1} \\
\mathrm{Q}^{1} \longrightarrow \mathrm{Q}+h v
\end{gathered}
$$

pected to be the best quencher in any triplet to singlet mechanism ${ }^{39}$, but it is not in terms of $\Delta H^{\neq}$. It should be noted, however, that 9,10-dibromoanthracene is the most efficient acceptor with respect to the observed quantum yield of (corrected) sensitized fluorescence.

Our data are too preliminary to allow us to generate any firm conclusions concerning the mechanism by which $\Delta H^{\neq}$and $\Delta S^{\neq}$are caused to vary to such extremes. However, it does seem quite apparent that the electronic structure of the acceptor is playing a major role in determining the electronic interactions which occur in this remarkable 'enthalpy catalysis' of aromatic energy acceptors.

\section{THE THERMOLYSIS AND PHOTOLYSIS OF NAPHTHVALENE}

Katz, Wang and Acton ${ }^{40}$ have recently reported a brilliant synthetic route to benzvalene (XXI) and naphthvalene (XXII). In a collaborative effort, we have examined the thermolysis and photolysis of XXI and XXII in a spectrophotofluorimeter, to determine if electronically excited products are produced. Although results on the thermolyses have been inconclusive to date, the data achieved on photolysis of XXII at $77^{\circ} \mathrm{K}$ allow some definitive and very striking conclusions to be made about naphthvalene's photochemistry.

Excitation of XXII in a methyl cyclohexane glass at $77^{\circ} \mathrm{K}$ revealed the initial occurrence of two emissions, one short-lived emission maximizing near $320 \mathrm{~nm}$ which is assigned to naphthvalene fluorescence on the basis of its spectral similarity to the known fluorescence of XXII. Of greater interest is the second, long-lived emission maximizing at about $520 \mathrm{~nm}$ which is

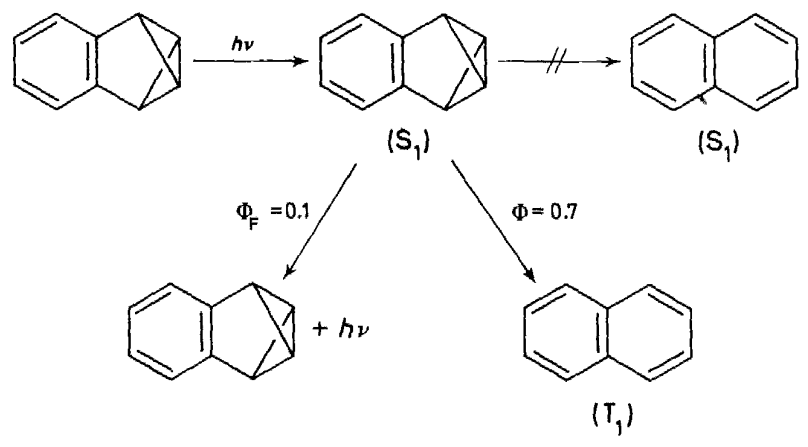

Figure 5. Photochemical conversion of naphthvalene into naphthalene. 


\section{ELECTRONICALLY EXCITED ORGANIC MOLECULES}

assigned to naphthalene phosphorescence, based on comparison of the lifetime and spectral distribution of this emission with that of an authentic sample of naphthalene. From the known phosphorescence yield of naphthalene, we can calculate that the quantum yield of the reaction is about 0.6 to 0.7 ! Thus we have uncovered another example of an efficient formation of an excited state product. The results of this research are summarized in Figure 5.

\section{CONCLUSION}

After consideration of the dearth of examples of photoreactions which produce electronically excited products, Hammond ${ }^{27}$ concluded that 'It seems unlikely that there will be any large number of systems in which a given chemical change is vastly more rapid in excited states than in corresponding ground states, unless the chemical change is driven by internal conversion of electronic energy.' He meant by this that reactions of the type $\mathrm{R} \star \rightarrow P$ will, in general, dominate $R^{\star} \rightarrow P^{\star}$ followed by $P^{\star} \rightarrow P$. Förster ${ }^{35}$ has suggested that the potential surfaces interconnecting $R^{\star}$ and $P^{\star}$ must be unfavourable for interconversion, and that a wide separation be maintained between the potential surfaces of $P^{\star}$ and $P$. This point of view is similar to that expressed by Dougherty ${ }^{36}$. The same types of ideas seem to be transferable to the description of thermal reactions which produce electronically excited products. The problem with these attitudes is that, while they are theoretically valid and provide us with a certain amount of insight, they do not immediately suggest the types of structures which will meet the requirement of producing electronically excited products. To begin with, it is non-trivial to surmount the problem

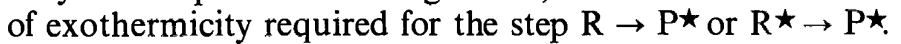

The two examples discussed here do have some features in common which might be of assistance in deciding what kinds of reactions might have the best chance of forming electronically excited products. Both involve: (a) a four-electron pericyclic reaction and (b) release of an enormous amount of energy if the path $\mathrm{R} \rightarrow \mathrm{P}$ or $\mathrm{R}^{\star} \rightarrow \mathrm{P}$ were to be followed without the intervention of $P^{\star}$. Intuitively, we expect that a chemical analogue to the spectroscopists' Franck-Condon principle should exist. In other words, reactions involving conversion of large amounts of electronic excitation energy into vibrational energy should be slow, relative to available paths which avoid such a situation, i.e. step-wise processes such as $\mathrm{R} \rightarrow \mathrm{P}^{\star} \rightarrow \mathrm{P}$ and $\mathrm{R}^{\star} \rightarrow$ $\mathrm{P}^{\star} \rightarrow \mathrm{P}$ might be favoured when the exothermicity of the overall reaction is very large. Perhaps then the problem is that, in general, molecular motions which allow the proper intersection of the energy surfaces of $R$ and $P^{\star}$ or $\mathrm{R}^{\star}$ and $\mathrm{P}^{\star}$ are not favourable. In this regard, it is intriguing to note that both of the reactions leading to excited state products considered in this paper, are formally pericyclic in nature. We do not wish to imply that they are required to be concerted, however, but merely that a $2 \sigma \rightarrow 2 \pi$ interconversion is involved in both cases.
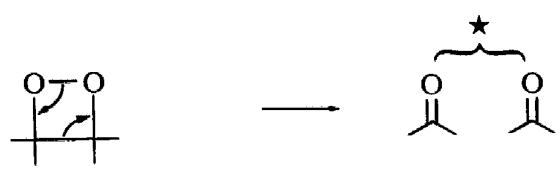


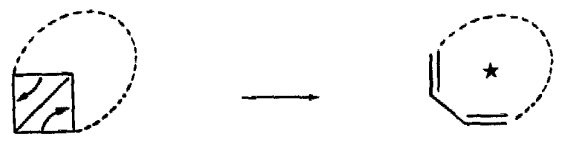

Thus, we can speculate that a felicitous blend of high exothermicity and proper molecular motions contrives to allow efficient formation of electronically excited products from V and XXII.

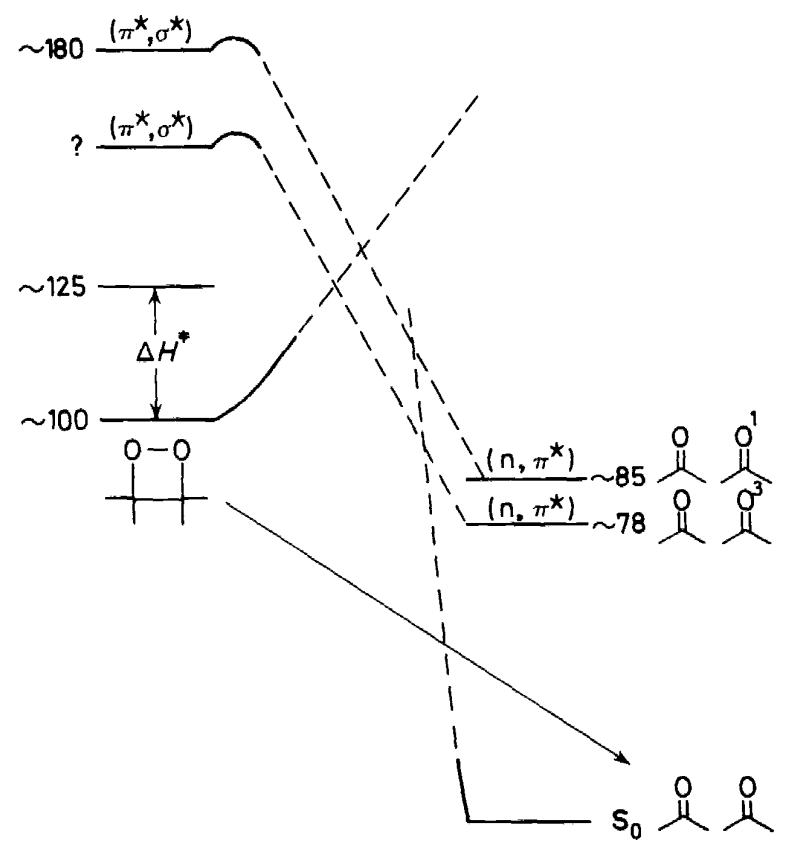

Figure 6. Possible state correlation diagram depicting the fragmentation of tetramethyl-1,2dioxetane. Energies in $\mathrm{kcal} / \mathrm{mole}$. Not drawn to scale.

In conclusion, it is revealing to consider an analysis of the state correlation of decomposition of 1,2-dioxetanes. Kearns ${ }^{1}$ has pointed out that the ground electronic state of 1,2-dioxetanes might correlate with an electronically excited state of the carbonyl fragment. Thermochemical considerations allow only one carbonyl fragment to be formed in an electronically excited state, which, in turn is required to be $n, \pi^{\star}$ (Figure 6). In an incisive anticipation of our results, Kearns noted that 'there may be a crossing of the potential energy curves for excited states (of products) and the ground state (of dioxetane). While small distortions from $C_{2 v}$ symmetry could prevent crossing of the ground state with an excited singlet curve, crossing of an excited triplet state could occur... one of the carbonyl ketones could be left in an excited triplet state as a result of the expected curve crossing... and dioxetanes should be photochemically unstable with respect to cleavage.' Even though this analysis applies strictly to a thoroughly concerted, one-step mechanism for decomposition, we feel that the effective mechanistic difference will be slight between a two-step rate-determining biradical formation followed by rapid 


\section{ELECTRONICALLY EXCITED ORGANIC MOLECULES}

cleavage of the $\mathrm{C}-\mathrm{C}$ bond and a one-step process with advanced cleavage of the $\mathrm{O}-\mathrm{O}$ bond relative to the $\mathrm{C}-\mathrm{C}$ bond.

\section{ACKNOWLEDGEMENTS}

The authors are indebted to many people for helping them to perform the experiments and to shape the ideas presented in this paper. Professor Karl Kopecky generously provided them with a detailed synthesis of V. Mr Mark Niemczyk skillfully synthesized $\mathrm{V}$ and executed some of the preliminary experiments with V. To Professors Emil White, David Kearns and William Richardson they are grateful for stimulating and concept-shaping discussions of the mechanism of dioxetane decomposition. Dr Richard Hautala suggested and executed the rise time search for an intermediate. Professor Thomas Katz, Mrs Eileen Carnahan and Mr Arthur Lyons collaborated with them on the experiments and interpretation of naphthvalene photochemistry.

The generous financial support of this work in the form of a NATO Fellowship to P. Lechtken and grants from the Air Force Office of Scientific Research (Grant AFOSR-1848D) and The National Science Foundation (Grant NSF-GP-26602x) is gratefully acknowledged.

\section{REFERENCES}

1 D. R. Kearns, Chem. Rev. 71, 395 (1971).

2 J. Calvert and J. N. Pitts Jr, Photochemistry, p 443. Wiley: New York (1965).

3 J. E. Leffler and J. W. Miley, J. Amer. Chem. Soc. 92, 7005 (1971).

4 P. R. Story and P. Busch, Advanc. Organic Chem. 8, 67 (1972).

${ }^{5}$ R. Criegee and R. Huber, Chem. Ber. 103, 1855, 1862 (1970).

${ }^{6}$ S. R. Fahrenholtz and A. M. Trozzolo, J. Amer. Fhem. Soc. 93, 251 (1971) and references therein.

7 C. Walling and M. J. Gibian, J. Amer. Chem. Soc. 87, 3413 (1965); Photosensitized decomposition of peroxides may be complicated by non-vertical energy transfer and 'chemical sensitization': P. S. Engel and B. M. Monroe, Advanc. Photochem. 8, 245 (1971).

8 M. M. Rauhut, Accounts Chem. Res. 2, 80 (1969); F. McCapra, Quart. Rev. 20, 485 (1966);

K. D. Gunderman, Chemilumineszenz Organischer Verbindungen, Springer: New York (1968).

${ }^{9}$ F. H. Johnson and Y. Haneda, Bioluminescence in Progress, Princeton University Press: Princeton, N.J. (1966).

10 A product called 'Coolite' is available commercially as a flexible plastic rod which, when bent, cracks an interior glass tube whose ingredients initiate a chemiluminescent reaction.

11 K. R. Kopecky and C. Mumford, Canad. J. Chem. 47, 709 (1969);

C. Mumford, PhD Dissertation, University of Alberta (1969).

12 S. Mazur and C. S. Foote, J. Amer. Chem. Soc. 92, 3225 (1970).

13 P. D. Bartlett and A. P. Schaap, J. Amer. Chem. Soc. 92, 3223 (1970);

A. P. Schaap and P. D. Bartlett, J. Amer. Chem. Soc. 92, 6055 (1970).

14 W. Adam and J.-C. Liu, J. Amer. Chem. Soc. 94, 2894 (1972).

15 H. E. O'Neal and W. H. Richardson, J. Amer. Chem. Soc. 92, 6553 (1970); W. H. Richardson, M. B. Yelvington and H. E. O'Neal, J. Amer. Chem. Soc. 94, 1619 (1972) and earlier papers.

16 P. R. Story, E. A. White and J. A. Alford, J. Amer. Chem. Soc. 94, 2143 (1972).

17 N. J. Turro et al., Accounts Chem. Res. 5, 92 (1972);

J. C. Dalton and N. J. Turro, Annu. Rev. Phys. Chem. 21, 499 (1970).

18 S. Murov and G. S. Hammond, J. Phys. Chem. 72, 3797 (1968).

19 G. Taylor, Chem. Phys. Letters, 10, 355 (1971).

20 T. Wilson and A. P. Schaap, J. Amer. Chem. Soc. 93, 4126 (1971). 


\section{NICHOLAS J. TURRO AND PETER LECHTKEN}

21 S. W. Benson and H. E. O'Neal, Kinetic Data on Gas Phase Unimolecular Reactions, NSRDSNBS 21, US Govt Printing Office: Washington, D.C., 20402;

M. R. Willcott, R. L. Cargill and A. B. Sears, Prog. Phys. Org. Chem. 9, 1 (1972).

22 E. H. White, J. Wiecko and D. Rosewell, J. Amer. Chem. Soc. 91, 5194 (1969);

E. H. White, J. Wiecko and C. C. Wei, J. Amer. Chem. Soc. 92, 2167 (1970).

23 H. Güsten and E. F. Ullman, Chem. Commun. 28 (1970).

24 J. C. Dalton, P. A. Wriede and N. J. Turro, J, Amer. Chem. Soc. 92, 1318 (1970).

25 N. J. Turro and P. Lechtken, J. Amer. Chem. Soc. 94, 2886 (1972).

26 J. E. Leffler and E. Grundwald, Rates and Equilibria of Organic Reactions. Wiley: New York (1963);

See however, R. C. Petersen, J. Org. Chem. 3133 (1964).

27 G. S. Hammond, Advanc, Photochem. 7, 373 (1969).

${ }^{28}$ S. Glasstone, K. J. Laidler and H. Eyring, The Theory of Rate Processes, McGraw-Hill: New York (1941).

29 G. W. Robinson and R. P. Frosch, J. Chem. Phys. 37, 1962 (1962); 38, 1187 (1963);

R. S. Berry, Record. Chem. Progress 31, 9 (1970).

30 R. B. Woodward and R. Hoffmann, The Consercation of Orbital Symmetry, Academic Press: New York (1970).

${ }^{31}$ K. Fukui, Accounts Chem. Res. 4, 57 (1971); Fortschr. Chem. Forschung 15, 1 (1970); M. J. S. Dewar, The Molecular Orbital Theory of Organic Chemistry, McGraw-Hill: New York;

H. E. Zimmerman, Angew. Chem. (Internat. Ed. Engl.), 8, 1 (1969).

32 C. Walling and P. J. Wagner, J. Amer. Chem. Soc. 86, 3368 (1964);

C. Walling and A. Padwa, J. Amer. Chem. Soc. 85, 1593 (1963);

C. Walling, Pure Appl. Chem. 15, 69 (1967).

${ }^{33}$ H. Gebelein and J. Jortner; Theor. Chim. Acta, 25, 143 (1972);

R. G. Gilbert and I. G. Ross, Austral. J. Chem. 24, 1541 (1971): The cis-trans-isomerization of certain ethylenes was once thought to involve the crossing of a ground state to a triplet state potential energy surface. Recent work, however, has cast this theory into serious doubt: see R. B. Cundall, Prog. Reaction Kin. 2, 165 (1964).

${ }^{34}$ S. K. Lower and M. A. El-Sayed, Chem. Rev. 66, 199 (1966);

S. P. McGlynn, F. J. Smith and G. Cilento, Photochem. Photobio. 3, 269 (1964).

35 Th. Förster, Pure Appl. Chem. 24, 443 (1970);

J. Menter and Th. Förster, Photochem. Photobio, 15, 289 (1972).

${ }^{36}$ R. C. Dougherty, J. Amer. Chem. Soc. 93,7187 (1971).

37 M. M. Rauhut et al. J. Amer. Chem. Soc. 89, 6515 (1967).

38 D. R. Roberts and E. H. White, J. Amer. Chem. Soc. 92, 4861 (1970).

39 R. F. Vassilev, Progr. Reaction Kin. 4, 305 (1967); Russ. Chem. Rev. 39, 529 (1970).

40 T. J. Katz, E. J. Wang and N. Acton, J. Amer. Chem. Soc. 93, 3782 (1971). 